\title{
Chinese Consumers' Perception of Organic Food and the Associated Purchase Behavior
}

\author{
Hailin Chen \\ Emporia State University
}

Joyce Zhou

University of Louisiana Monroe

\author{
Jun Yu \\ University of Louisiana Monroe
}

\begin{abstract}
Organic food is a relatively new phenomenon in China, one of the largest consumer markets. The purpose of this research is to explore Chinese consumers' perception of organic food and the associated purchase behavior. To this end, a survey was conducted among Chinese consumers. Findings indicate there is some acceptance of organic food products among Chinese consumers based on their beliefs of the benefits of these products. However, current interest in buying organic food products is not high. The findings have potential to help organic food businesses seek out new market opportunities, improve product positioning, and select the most effective channels of distribution. Implications for both future research and marketing practice are discussed.
\end{abstract}

Keywords: organic food, emerging market, Chinese consumers, marketing strategy

\section{INTRODUCTION}

Population growth has put pressure on food production. In order to increase the output of agricultural products to feed the world's growing population, producers have used biological and chemical methods to improve the efficiency of agricultural production. However, adoption of these methods has led to consumers raising concerns about food safety (Basha et al., 2015). One solution for consumers with these concerns is to purchase organic food products. As the name indicates, organic food is grown in accordance with the principles and practices of organic agriculture. Organic agriculture is socially, ecologically, and economically sustainable (Bourn \& Prescott, 2002), avoiding the usage of synthetic fertilizers and pesticides during production, processing, and storage (Shafie \& Rennie, 2012). Furthermore, organic products do not contain any genetically modified materials to achieve sustainability of agriculture. For organic livestock, producers do not use growth hormones, antibiotics and other chemicals to accelerate livestock growth (Basha et al., 2015).

Since the 1990s, the organic food industry has grown dramatically in the United States with nearly $20 \%$ annual growth rate. The worldwide organic food market also has developed rapidly due to negative 
perception of intensive farming systems and concerns about human health and environment (Akaichi et al., 2012). In China, the rapid economic development is accompanied by the modernization of agricultural food production. Meanwhile, Chinese agriculture heavily relies on modern chemical products to enhance land productivity to increase output, causing problems related to human health and the environment (Ye et al., 2002). Studies have shown dangerous food safety incidents caused by chemicals used in food production (Dominique, 2006). Increasing concerns about human health and environmental protection have resulted in increasing demand for organic foods (Li, 2006; Yin et al., 2008; Xie et al., 2015).

In this context, the aim of this research is to study Chinese's consumers' perception and associated consumption patterns regarding organic food. We also explore consumers' intention for future organic food consumption. With information obtained from studies like this one, the organic food marketer targeting the Chinese market could develop a sustainable strategy to grow their business and increase consumers' demand for their products there.

\section{LITERATURE REVIEW}

Over the past several decades, consumers' interest in organic food has grown rapidly (Zepeda \& Deal, 2009). Kirscht (1974) discusses the health belief model which can be used to frame decisions about consumers' health-motivated diet, and pointed out that consumers' behaviors are motivated by the tradeoff of the perceived benefit minus the threats, barriers, and costs of the dietary change. Dimitri and Greene (2002) provide evidence that some organic food consumers were motivated by health concerns. Besides health concerns, perceived food quality is also an important factor in organic food consumption (Padel \& Foster, 2005; Fotopoulos, 2000; Magnusson et al., 2001). Kulikovski and Agolli (2010) find that most organic food consumers perceived organic products have higher quality than traditional food. Xie et al. (2015) also have similar results in their research. The majority of their respondents think organic food have better taste and are fresher.

In recent years, food safety is clearly has attained a growing importance in consumers' mind and has been the major factor in the purchase of organic food (Padel \& Foster, 2005; Baker et al., 2004; Zanoli \& Naspetti 2002; Michelidou \& Hassan, 2008). Food safety concerns, especially regarding low or no pesticide residues, is the key reason for consuming organic food (Bourn \& Prescott, 2002). In addition, value is another motivation for consuming organic food. Many studies have shown that value has a major influence on driving consumers' decision-making towards organic food consumption (Krystallis \& Chryssohoidis, 2005). Kulikovski and Agolli (2010) indicate in their research that consumers consider organic food valuable to their lives. Other studies also show an association between value placed on organic food and organic food consumption (Arvola et al., 2008; Winter, 2006).

Stern (2000) develops a value-belief-norm (VBN) theory to explain the value and norm-activation theory of environmentally significant behavior. Essentially, it examines values that underlie actions. VBN contains three theories --- activism and non-activist public sphere behaviors (memberships, supporting policies), private sphere behaviors (recycling or buying organic foods), and behaviors within organizations (promoting energy efficiency). He shows that when individuals are aware of adverse consequence to themselves and others, their moral norms will be activated (Stern, 2000). A number of studies have indicated that ethical consumerism is a worldwide trend and moral responsibility is a relevant motivation, which drives consumers' buying behavior (Carrigan et al., 2004; Shaw \& Shiu, 2002). Consumers consider themselves as ethical consumers when they buy organic food, although it is for environmental considerations (Browne et al., 2000).

Research has revealed that consumer trust in organic food certification and labelling has an influence on consumers' willingness to buy organic products. Once they trust a particular brand, they will place their faith in the products (Bellows \& Onyango, 2008). Sangkumchaliang and Huang (2012) confirm similar results in their research. Increasing awareness of organic food certification and labelling and enhancing consumer trust could be the most effective way to increase market shares for brands.

Various publications have demonstrated that the price of organic food is playing a major role in organic food purchase intention, and price seems to be the main barrier to purchasing organic food (Padel \& Foster, 
2005; Hughner et al., 2007; Zanoli \& Naspetti, 2002). Smith (2010) conducted research about consumer reactions to organic food price premiums in the United States and indicated American consumers do not purchase organic food regularly because of the increased price of organic food (Smith, 2010). Xie et al. (2015) found out the similar results in Chinese organic food market. Most Chinese consumers hesitate to buy organic food due to the high prices compared with those of traditional food products. Furthermore, young consumers refuse to buy organic food because of their limited income (Xie et al., 2015).

\section{METHODOLOGY}

It is clear that several major issues regarding consumption of organic food products have received much attention in the literature. However, no research has comprehensively examined consumers' perception of organic food and shopping behavior involving organic food, especially in the Chinese market. This exploratory study aims to provide a preliminary understanding of Chinese consumers' perception of organic food and their purchase behavior involving organic food. To this end, we developed a set of questions focused on health, quality, safety, value, ethic, trust, and price consciousness, respectively. Moreover, we explore Chinese consumers' future shopping intention and preferred shopping venues. Then the data collected will be coded and interpreted by researchers to extract meaningful patterns.

\section{Sample and Data Collection}

The data were collected in central and eastern China through electronic distribution through WeChat, a popular Chinese social media app. We were able to receive responses from 172 participants. The participants, including 42 males and 130 females, came from all walks of life. The vast majority of them were between 18 to 28 years old, did not have child, and worked full time. Almost all respondents have a bachelor's degree or higher with a monthly income level between RMB 2,000 - RMB10, 000.

\section{Research Instrument}

Our questionnaire has three sections. The first part was designed to collect organic food consumers' shopping behavior and shopping history, including questions about the share of household shopping they were responsible for, frequency of organic food purchase, organic food shopping venues, and preferred future organic food shopping venues.

The second and more detailed section of our survey asked respondents to describe their beliefs about organic food, explain why they buy organic food, whether they would buy more organic food under certain circumstances, and what kinds of organic products they would like to purchase in the next 3 months and 6 months. The respondents were asked to rate a series of statements on a 1 to 7 scale, where 1 stands for "strongly agree" and 7 "strongly agree". Questions about reasons for purchasing organic food were organized into 7 different parts, each representing one variable and containing 3-4 statements. These questions were created as a result of examining existing literature. The format for this type of questions had been shown valid in survey design (Kulikovski \& Agolli, 2010; Mutlu, 2007). Respondents also were asked to select the organic food product types that they would like to consume in the future. Questions on respondents' demographic information include items such as gender, age, household size, number of children in the household, education level, employment status, and income level.

\section{RESULTS}

\section{Organic Food Consumer Shopping History}

Among the respondents, thirty percent (30\%) are responsible for $15 \%$ of household grocery shopping. Only twenty-six percent $(26 \%)$ of them are responsible for sixty percent or higher. With regard to organic food shopping frequency, five percent (5\%) of them purchase organic food 5-7 times a week, twelve percent (12\%) 3-4 times a week, thirty-three percent (33\%)1-2 times a week, nineteen percent (19\%) once a month, and thirty percent $(30 \%)$ less than once a month. Fourteen percent $(14 \%)$ of our participants indicate that they purchased organic food for the first time five years ago, sixteen percent (16\%) two to five years ago, 
twenty-four percent $(24 \%)$ one to three years ago, twenty-four percent $(24 \%)$ within the past year, and twenty-two percent (22\%) within the past six months. In terms of organic food shopping venues, seventyseven percent (77\%) of our respondents indicate that they buy organic food products at supermarket chains and seventy- seven percent (77\%) of them indicate that they would like to see more organic food products in supermarket chains.

\section{FIGURE 1 \\ VENUES WHERE PARTICIPANTS HOPE TO SEE MORE ORGANIC FOOD PRODUCTS}

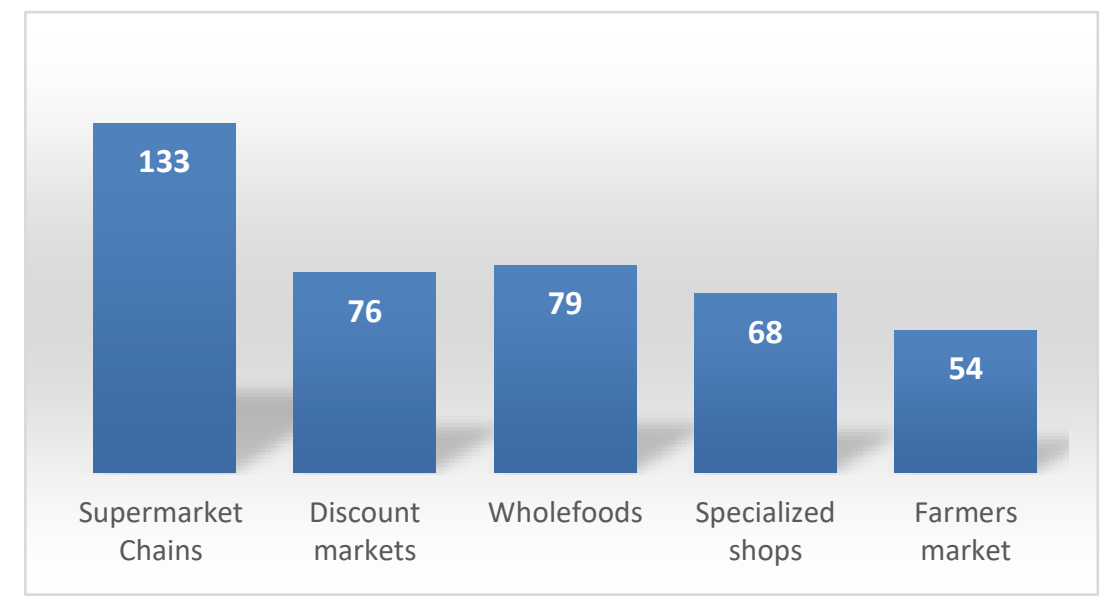

\section{Beliefs of Organic Food Products}

The vast majority of the participants thought organic food is healthy. Twenty-four percent (24\%) of them somewhat agree that organic food is healthy, and sixteen percent $(16 \%)$ agree and thirty-nine percent (39\%) strongly agree. The average score for health is 5.53. Thirty percent (30\%) of them somewhat agree that organic food has high nutritional value, whereas seventeen percent (17\%) agree and twenty-three percent $(23 \%)$ strongly agree. The average score is 5.1 . With regard to "products are grown in harmony with nature", twenty percent (20\%) somewhat agree, and nineteen percent $(19 \%)$ agree and thirty-five percent $(35 \%)$ strongly agree. The average score for this statement is 5.47 . About safety consideration, eighteen percent $(18 \%)$ of our respondents somewhat agree that organic food is free from chemical pesticides and fertilizers, and eighteen percent (18\%) agree and thirty-seven percent (37\%) strongly agree. The average score is 5.44. About environment and animal friendly technique consideration, twenty-six percent $(26 \%)$ somewhat agree that environment and animal friendly techniques are used in production of organic food, and seventeen percent (17\%) agree and thirty percent (30\%) strongly agree. The average score for this consideration is 5.28. Regarding genetically modified techniques, sixteen percent (16\%) of our participants somewhat agree, and thirty-six percent (36\%) strongly agree. The average score is 5.34 . In terms of certified organic agriculture products, seventeen percent $(17 \%)$ of them somewhat agree that organic food products are certified organic agricultural products, and eighteen percent (18\%) agree and thirty-six percent (36\%) strongly agree. The average score for this statement is 5.39. Obviously, consumers hold positive views about organic food products. 


\section{FIGURE 2 \\ CONSUMERS' PERCEPTION ON ORGANIC FOOD PRODUCTS}

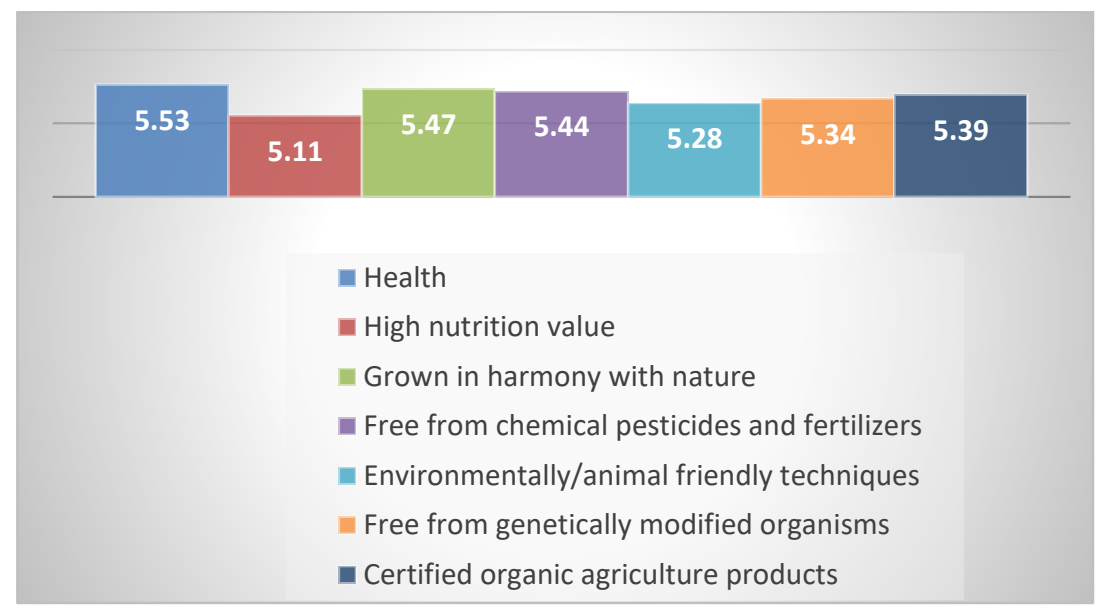

\section{Reasons for Purchasing Organic Food Products}

The majority of our respondents indicated that they buy organic food products for health reasons. Twenty percent $(20 \%)$ of our respondents somewhat agree that organic food products can help them maintain long-term health, with which seventeen percent (17\%) agree and forty percent (40\%) strongly agree. Moreover, sixty-six percent $(66 \%)$ of the respondents believe organic food is healthier than conventional food. The average score on the health factor is 5.37. About organic food quality, sixty-seven percent $(67 \%)$ believe organic food has higher quality than traditional food. Meanwhile, twenty-three percent $(23 \%)$ of the respondents somewhat agree that organic food is less associated with health risk and thirty percent (30\%) strongly agree. The average score on this factor is 5.14 . With regard to food safety, twenty-four percent (24\%) somewhat agree that organic food is safer and twenty-six percent (26\%) strongly agree. Twenty-two percent $(22 \%)$ of the respondents somewhat agree that organic food is not genetically modified food and twenty-three percent (23\%) strongly agree. Furthermore, twenty-two percent (22\%) somewhat agree that organic food does not contain pesticide and fertilizer and twenty-six percent (26\%) strongly agree. The average score for food safety considerations is 5.12. With regard to organic food value, fifty-five percent (55\%) respondents think organic food is an important part of their lives and sixty-four percent $(64 \%)$ deem organic food as valuable for them. The average score for this factor is 4.89 . Sixty-six percent $(66 \%)$ consider themselves as an ethical consumer by buying organic food products. Furthermore, seventy-one percent (71\%) think organic food is produced more ethically and seventy-seven percent (77\%) believe organic food products are more environmentally friendly. The average score for this factor is 5.29. Our questionnaire results also showed that seventy-two percent (72\%) of the respondents think organic food labelling gives them a feeling of trust and seventy-two percent (72\%) point out that they have confidence in organic food producers. The average score on the trust factor is 5.12. Seventy-four percent (74\%) respondents state that the price of organic food is high, but fifty-six percent $(56 \%)$ indicate that they do not mind paying more for organic food products. The average score for price consciousness is 5.27.

Seventy-six percent (76\%) of our respondents indicate that they would like to buy more organic food products if the prices are lower and the products more accessible. Seventy-seven percent (77\%) of the respondents indicate that they want to buy more organic food products when they earn more income. Eighty percent $(80 \%)$ of them would like to buy more organic food products if there are more assortments available. In the meantime, eighty-one percent of the respondents prefer to consume more organic food products if those products have better appearance and taste. 


\section{FIGURE 3 \\ ORGANIC FOOD CONSUMERS' PURCHASE REASON}

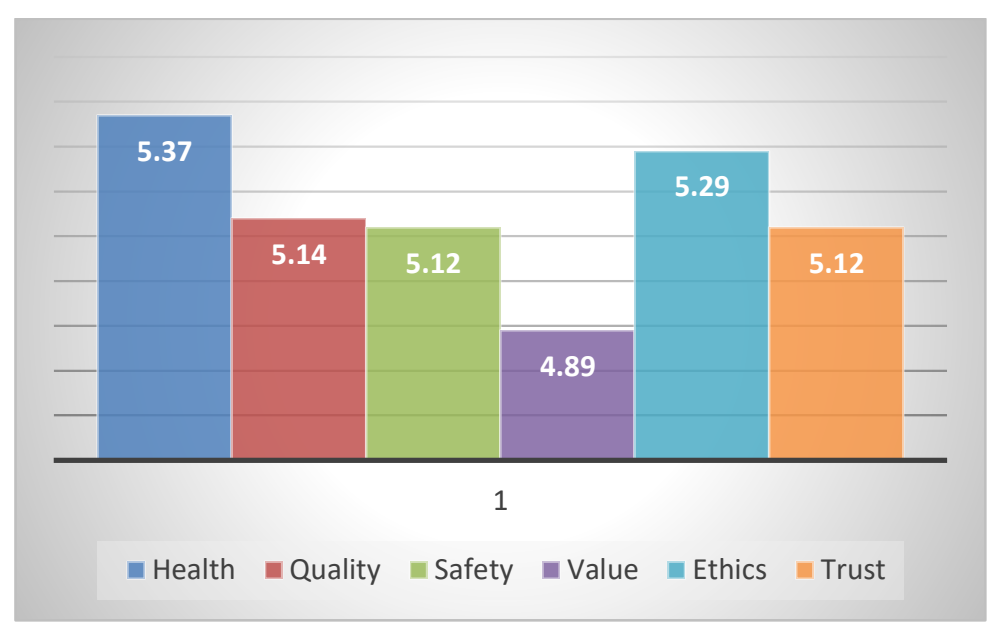

FIGURE 4 ORGANIC FOOD PRICE IS EXPENSIVE

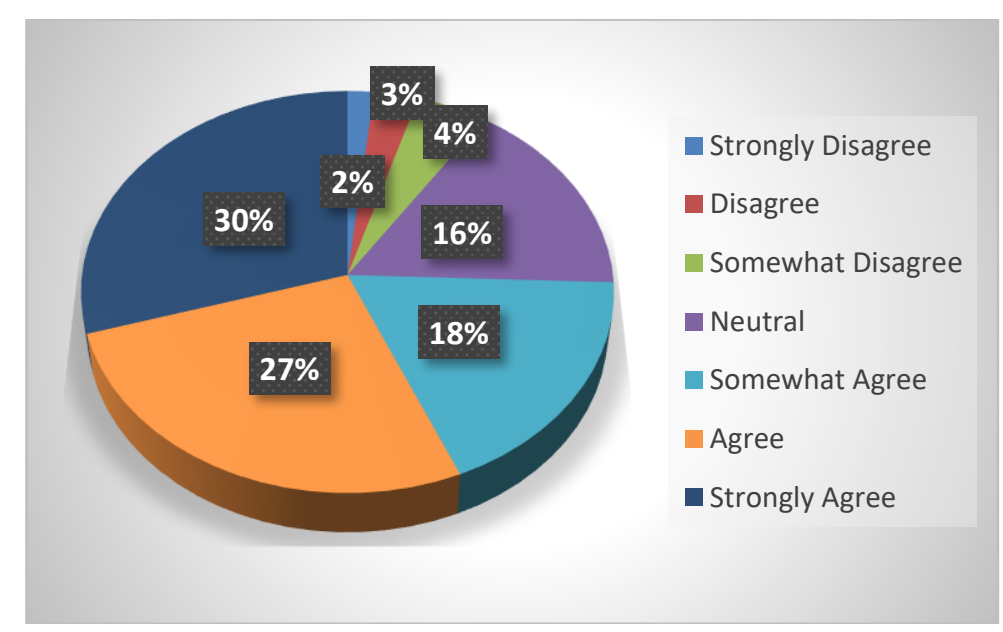

\section{Future Organic Food Consumption}

Regarding intention to consume organic food products in the future, the data also show that eightyeight percent $(88 \%)$ of the respondents would like to purchase fresh vegetables within three months and eighty-one percent $(81 \%)$ within 6 months. Eighty-six percent $(86 \%)$ would like to purchase fresh fruit within three months and eighty-one percent $(81 \%)$ within 6 months. In addition, more than half of the respondents reveal that they also would like to buy meat products, dairy products, and cereals in the next 6 months. Almost half of them also indicated that they would like to purchase bread and bakery products as well. 
FIGURE 5

FUTURE THREE MONTH ORGANIC FOOD CONSUMPTION INTENTION

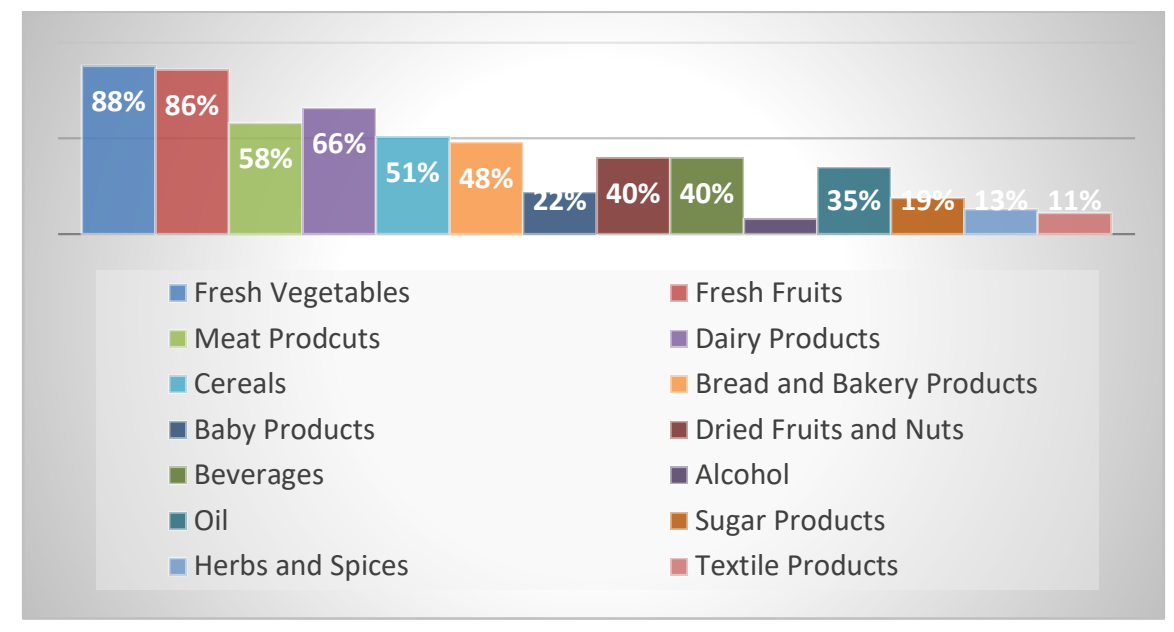

\section{FIGURE 6 \\ FUTURE SIX MONTH ORGANIC FOOD CONSUMPTION INTENTION}

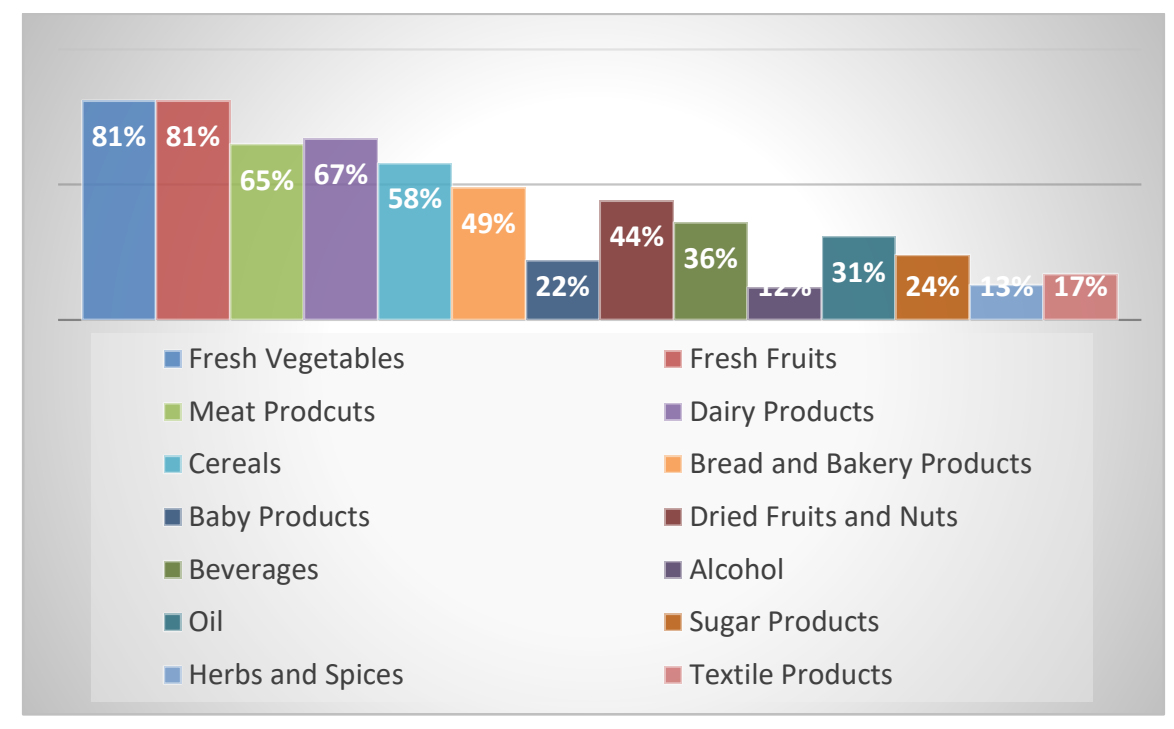

\section{DISCUSSION}

This research examines consumer perception and shopping behavior regarding organic food products. The results of our research show that most organic food products consumers are responsible for some sort of grocery shopping and some of them are completely responsible for their families' grocery shopping. Also, most consumers established their organic food consumption behavior in the last three years. A significant number of consumers indicated that they started buying organic food in the last six months. Thus, it appears that the organic food market is expanding and will further develop. Another finding worth noting is that most organic food consumers prefer to buy organic food products in supermarket chains. Moreover, they wish to see more organic food products in these supermarket chain. Putting these together, we can see the importance of continuing the effort to educate Chinese consumers about organic food and promote organic food products, while making efforts to make organic food products more accessible, especially in supermarket chains. These efforts would directly lead to increased sales of organic food 
products. Since creating product awareness is a long-term effort, the findings here bode well for producers that realize the importance of product promotion in this emerging market.

Several observations from the data on beliefs of organic food products should be noted. First, most consumers consider organic food to be healthy. Furthermore, they believe organic food is healthier than conventional food. Another significant finding is that most consumers deem organic food as having higher nutritional value, higher safety standards, and more environment and animal friendly. As such, organic food consumers hold positive views about organic food products. Meanwhile, they believe organic food products can bring benefits to their health. A significant number of respondents believe organic food products are certified. This implies consumers has a certain amount of trust in organic food products. Therefore, it would serve organic food businesses well to continue to strengthen the image of their products to maintain and enhance product appeal.

The results of our research indicate that most respondents buy organic food products for reasons related to health, food quality, food safety, value, trust, and environmental consciousness. Moreover, they believe eating organic food can help maintain their moral standards. This is another issue organic food marketers can amplify in communications with consumers. In addition, fresh vegetables, fresh fruits, meat products, dairy products, and cereals are the main product categories which consumers would like to purchase in the future. Therefore, it would be highly beneficial for marketers to continue to promote organic food products along the lines of health, quality, safety, value, trust, and environmental protection. It would also be very helpful for marketers to make the efforts to make any positive information on environmental protection regarding organic food products available to consumers, as respondents indicate that they would like to engage in ethical consumption of organic food.

Another important finding is that the vast majority of the respondents are price sensitive and seem to be deterred by high prices of organic food products. Most respondents also indicated that they would like to buy organic food products if prices are lower, if there are more assortments, and if organic food products have better appearance and taste. It is reasonable to think that price is an important factor in organic food purchase, and marketers need to carefully plan for their pricing strategy for further growth in this market.

Ethical consumers normally translate their concerns or attitudes toward society and environment into actual purchase and consumption behavior (De Pelsmacker, Driesen, \& Rayp, 2005). Organic food consumers actually have put this into practice, as evident in this research. Many respondents of this research prefer to buy organic food products because of their ethical beliefs. Hence, marketers need to deliver positive information about their products through their communications of corporate social responsibility to organic food consumers. Last but not least, the organic food market in China is still at the early stage of development (Gan et al., 2014, 2014). Most respondents in our study started consuming organic food in last year or last three years, as found in this study. Therefore, it is pivotal to promote various attributes of organic products as well as building trust in organic food products to encourage consumer purchase. Over the past decade, many Chinese media reported the food scandals and consumers' concern on food safety (Gan et al., 2014, 2014). It is an encouraging sign for organic food businesses as Chinese consumers search for healthy and safe food options.

\section{REFERENCES}

Akaichi, F., Nayga, R.M.J., \& Gil, J.M. (2012). Assessing consumers' willingness to pay for different units of organic milk: Evidence from multiunit auctions. Canadian Journal of Agricultural Economics, 60(4), 469-494.

Baker, S., Thomson, P.E., \& Engelken, J. (2004). Mapping the values driving organic food choice. European Journal of Marketing, 38(8), 995-1012.

Basha, M.B., Mason, C., Shamsudin, M.F., Hussain, H.I., \& Salem, M.A. (2015). Consumers Attitude Towards Organic Food. Procedia Economics and Finance, 31, 444-452.

Bellows, A.C., \& Onyango, B. (2008). Understanding consumer interest in organics: Production values vs. purchasing behaviour. Journal of Agricultural \& Food Industrial Organization, 6(2), 1-28. 
Bourn, D., \& Prescott, J. (2002). A comparison of the nutritional value, sensory qualities, and food safety of organically and conventionally produced foods. Critical Reviews in Food Science and Nutrition, 42(1), 1-34.

Browne, A.W., Harris, P.J.C., Hofny-Collins, A.H., \& Pasiecznic, N. (2000). Organic production and ethical trade: Definition, practice and links. Food Policy, 25, 69-89.

Carrigan, M., Szmigin, I., \& Wright, J. (2004). Shopping for a better world? An interpretive study of the potential for ethical consumption within the older market. Journal of Consumer Marketing, 21(6), 401-417.

De Pelsmacker, P., Driesen, L., \& Rayp, G. (2005). Do consumers care about ethics? Willingness to pay for fair trade coffee. Journal of Consumer Affairs, 39(2), 363-385.

Dimitri, C., \& Greene, C. (2002). Recent growth patterns in the U.S. organic food market. U.S. Department of Agriculture, Economic Research Services. Washington, DC.

Dominique, P. (2006). Pesticide residues still high in Chinese vegetables. Foodqualitynews.com. Retrieved June 9, 2017.

Fotopoulos, C., \& Krystallis, A. (2002). Purchasing motives and profile of Greek organic consumers: A countrywide survey. British Food Journal, 104(9), 730-764.

Gan, C., Tran, M.C., \& Cohen, D.A. (2014). Consumer attitudes toward the purchase of organic products in China. Faculty of Agribusiness \& Commerce Working Paper No. 15.

Hughner, R.S., McDonagh, P., Prothero, A., Shultz, C.J., \& Stanton, J. (2007). Who are organic food consumers? A compilation and review of why people purchase organic food. Journal of Consumer Behaviour, 6(2-3), 94-110.

Krischt, J.P. (1974). Research related to the modification of health beliefs. In the Health Belief Model and Personal Health Behavior, pp. 455-469.

Krystallis, A., \& Chryssohoidis, G. (2005). Consumers' willingness to pay for organic food: Factors that affect it and value. British Food Journal, 107(4-5), 320.

Kulikovski, V., \& Agolli, M. (2010, January). Drivers of organic food consumption in Greece. School of Economics \& Business Administration, International Hellenic University.

Li, X.J. (2006). Organic agriculture development background, status and exception in China. Farm and Produce Market Weekly, 42, 26-29.

Magnusson, M.K., Arvola, A., Koivisto Hursti, U., Åberg, L., \& Sjödén, P. (2001). Attitudes towards organic foods among Swedish consumers. British Food Journal, 103(3), 209-227.

Michaelidou, N., \& Hassan, L.M. (2008). The role of health consciousness, food safety concern and ethical identity on attitudes and intentions towards organic food. International Journal of Consumer Studies, 32, 163-170.

Padel, S., \& Foster, C. (2005). Exploring the gap between attitudes and behaviour. British Food Journal, 107(8), 606.

Sangkumchaliang, P., \& Huang, W.C. (2012). Consumers' perception and attitudes of organic food products in Northern Thailand. International Food and Agribusiness Management Review, 15(1), 87-102.

Shafie, F.A., \& Rennie, D. (2012). Consumer perceptions towards organic food. Social and Behavioral Sciences, 49, 360-367.

Shaw, D.S., \& Shiu, E. (2002). An assessment of ethical obligation and self-identity in ethical consumer decision-making: A structural equation modelling approach. International Journal of Consumer Studies, 26(4), 286-293.

Smith, A.C. (2010). Consumer reactions to organic food price premiums in the United States. Iowa State University.

Stern, P.C. (2000). Toward a coherent theory of environmentally significant behavior. Journal of Social Issues, 56(3), 407-424.

Winter, C. (2006). Organic foods. Journal of Food Science, 71(9), 117-124.

Xie, B., Wang, L., Yang, H., Wang, Y., \& Zhang, M. (2015). Consumer perceptions and attitudes of organic food products in Eastern China. British Food Journal, 117(3), 1105-1121. 
Ye, X.J., Wang, Z.Q., \& Li, Q.S. (2002). The ecological agriculture movement in modern China. Agriculture, Ecosystems and Environment, 92(2-3), 261-281.

Yin, S.J., Wu, L.M., \& Chen, M. (2008). Demand analysis for organic food based on the consuming willingness. Agricultural Technology and Economy, 5, 81-88.

Zanoli, R., \& Naspetti, S. (2002). Consumer motivations in the purchase of organic food. British Food Journal, 104(8-9), 643.

Zepeda, L., \& Deal, D. (2009). Organic and local food consumer behaviour: Alphabet theory. International Journal of Consumer Studies, 33, 697-705. 